\title{
PROPOSTA DE PROTOCOLO PARA DESCONTAMINAÇÃO DE EQUIPAMENTOS EM UNIDADE DE TERAPIA INTENSIVA
}

\section{PROTOCOL PROPOSAL FOR DECONTAMINATION OF EQUIPMENT IN INTENSIVE THERAPY UNIT}

\author{
PROPUESTA DE PROTOCOLO PARA DESCONTAMINACIÓN DE EQUIPOS EN UNIDAD DE TERAPIA \\ INTENSIVA
}

Juliana Ribeiro Mendes ${ }^{1}$, Marislei de Sousa Espíndula Brasileiro ${ }^{2}$

\begin{abstract}
RESUMO
Objetivo: Analisar a contaminação de equipamentos em uma unidade de terapia intensiva antes e após a limpeza e desinfecção e propor um protocolo para descontaminação. Métodos: Foram utilizados 14 swabs estéreis, umedecidos com soro fisiológico $0,9 \%$, rolados em seu próprio eixo, antes e imediatamente depois da limpeza e desinfecção com álcool 70\%, sobre superfícies de equipamentos de manipulação coletiva, em uma unidade de terapia intensiva, para realização de cultura laboratorial. Resultados: $\mathrm{Na}$ pré-desinfecção, apresentaram crescimento de staphylococcus coagulase negativo, a mesa de cabeceira, o teclado de computador e o telefone. O telefone continuou contaminado após a limpeza e desinfecção. A bancada de preparo de medicamento, o glicosímetro, a escala de enfermagem e o monitor não apresentaram contaminação antes nem após a limpeza / desinfecção. Conclusão: A contaminação de equipamentos na unidade de terapia intensiva e a desinfecção com álcool $70 \%$ foi comprovada; porém, é necessário observar, em cada unidade, a técnica de limpeza utilizada, principalmente nestes mesmos instrumentos que, frequentemente, são tocados pela equipe de saúde, propondo um protocolo para sua respectiva descontaminação.
\end{abstract}

Descritores: Unidades de terapia intensiva; Desinfecção; Infecção hospitalar; Segurança do paciente.

\section{ABSTRACT}

Objective: To analyze the equipment contamination in an intensive care unit before and after cleaning and disinfection and to propose a protocol for decontamination. Methods: We used 14 sterile swabs moistened with $0.9 \%$ saline, rolled on their own axis, before and immediately after cleaning and disinfection with $70 \%$ alcohol, on surfaces of collective manipulation equipment in an intensive care unit, to perform laboratory culture. Results: In the pre-disinfection, they presented growth of negative coagulase staphylococcus, the bedside table, the computer keyboard and the telephone. The phone remained contaminated after cleaning and disinfection. The drug preparation stand, the glucose meter, the nursing scale and the monitor did not present contamination before either after cleaning / disinfection. Conclusion: The study proved the equipment contamination in the intensive care unit and disinfection with $70 \%$ alcohol; however, it is necessary to observe in each unit, the cleaning technique used, mainly in the equipment in which they are frequently touched by the health team proposing a protocol for decontamination of equipment. Descriptors: Intensive care units; Disinfection; Crossl infection; Patient safety.

\section{RESUMEN}

Objetivo: Analizar la contaminación de equipos en una unidad de terapia intensiva antes y después de la limpieza y desinfección y proponer un protocolo para descontaminación. Métodos: Se utilizaron 14 swabs estériles humedecidos con suero fisiológico $0,9 \%$, rodados en su propio eje, antes e inmediatamente después de la limpieza y desinfección con alcohol 70\%, sobre superficies de equipos de manipulación colectiva en una unidad de terapia intensiva, para la realización de cultivo de laboratorio. Resultados: En la pre-desinfección presentaron crecimiento de staphylococcus coagulase negativo, la mesa de cabecera, el teclado de computadora y el teléfono. El teléfono continuó contaminado después de la limpieza y desinfección. La bancada de preparación de medicamento, el glucómetro, la escala de enfermería y el monitor no presentaron contaminación antes ni después de la limpieza / desinfección. Conclusión: La contaminación de equipos en la unidad de terapia intensiva y la desinfección con alcohol $70 \%$ fue comprobada; todavía es necesario observar, en cada unidad, la técnica de limpieza utilizada principalmente en los mismos equipos en los que, a menudo, son tocados por el equipo de salud, proponiendo un protocolo para su correspondiente descontaminación. Descriptores: Unidades de cuidados intensivos; Desinfección; Infección hospitalaria; Seguridad del paciente.

${ }^{1}$ Graduada em Enfermagem pelo Centro Universitário do Triângulo - UNITRI. ${ }^{2}$ Graduada e Licenciada em Enfermagem. Doutora em Ciências da Saúde pela Universidade Federal de Goiás. Doutora em Ciências da Religião pela Pontifícia Universidade Católica de Goiás. Docente na Pontifícia Universidade Católica de Goiás. https://doi.org/10.19175/recom.v7i0.2346 


\section{INTRODUÇÃO}

A contaminação ambiental por microrganismos, na unidade de terapia intensiva, aumenta o risco de os pacientes desenvolverem infecção relacionada à assistência à saúde (IRAS), principalmente, se o microrganismo for multirresistente. As IRAS são transmitidas, principalmente, pelas mãos dos profissionais de saúde, através do contato com superfícies próximas ao leito do paciente e com o uso de equipamentos médicos contaminados, aumentando, consideravelmente, os gastos aos serviços de saúde ${ }^{(1-2)}$.

As unidades de terapia intensiva são classificadas como áreas críticas, destinadas a pacientes graves, que necessitam de monitorização contínua e acompanhamento, 24 horas, da equipe de saúde. Os equipamentos e superfícies podem se tornar reservatórios de microrganismos se o processo de limpeza e desinfecção não for realizado de uma forma padronizada e eficiente ${ }^{(1,3-4)}$.

Vários estudos indicam a presença de microrganismos em materiais de uso diário pela equipe de saúde como: telefones, bancadas para preparo de medicamentos, eletrocardiograma, glicosímetros, estetoscópio, teclado de computador, aparelho telefônico, escala dos profissionais de enfermagem, uniformes utilizados dentro da UTI, colchões; e apontam que o processo de limpeza e desinfecção tem sido ineficaz e que, por isso, além da forte recomendação de higiene das mãos para prevenção de IRAS, o controle ambiental passa a ser essencial, uma vez que se torna fonte de transmissão cruzada de microrganismos quando contaminado ${ }^{(1-7)}$.

Desta forma, o processo de controle ambiental para descontaminação de equipamentos deve ser melhor avaliado pelos serviços de saúde, contribuindo para uma assistência segura e sem danos. O objetivo deste estudo é analisar os equipamentos estudados por Cordeiro et al. $^{(1)}$ e propor um protocolo para descontaminação dos equipamentos.

\section{MÉTODOS}

O estudo foi realizado em uma Unidade de Terapia Intensiva de um hospital de médio porte, situado no interior de Minas Gerais. Foram incluídos, na pesquisa, as superfícies de 8 equipamentos coletivos de manipulação frequente pela equipe de saúde do serviço. Foram utilizados 14 swabs, sendo divididos da seguinte forma: uma mesa de cabeceira (2 swabs), um teclado de computador (2 swabs), um telefone ( 2 swabs), uma bancada para preparo de medicamento (2 swabs), um glicosímetro (2 swabs), uma escala de enfermagem (2 swabs) e um monitor (2 swabs).

A coleta de dados foi realizada pela pesquisadora em um único momento, sendo coletados 2 swabs de cada equipamento, sendo um antes da limpeza e outro imediatamente após a limpeza deste, aguardando apenas a secagem do produto sem tempo definido. Os swabs foram identificados como antes e depois da limpeza e os equipamentos foram identificados com seu nome; não houve coleta de equipamentos repetidas.

Foram utilizados swabs estéreis e umedecidos com soro fisiológico 0,9\%, antes da coleta, foram rolados em seu próprio eixo sobre as superfícies analisadas antes e após a limpeza/desinfecção.

A execução da limpeza/desinfecção foi realizada com um pano descartável, específico para a limpeza/desinfecção de superfícies, embebido em álcool 70\%, sem preceder limpeza com agua e sabão, sendo friccionados em vários sentidos, até limpeza de sujidade aparente. Foi observado uma média de 3 fricções consecutivas sem secar o equipamento.

Os equipamentos analisados não haviam sido previamente limpos no dia da coleta. A limpeza dos equipamentos analisados após a coleta do swab foi realizada com uma luva de procedimentos e pano descartável padrão, para uso na limpeza de superfícies, que foi embebido em álcool 70\%. O mesmo pano foi utilizado para todos os equipamentos analisados.

Após as coletas, os swabs foram encaminhados para o laboratório terceirizado para cultura automatizada.

O desenvolvimento deste estudo atendeu às normas nacionais e internacionais de ética em pesquisa, não envolvendo seres humanos.

\section{RESULTADOS E DISCUSSÃO}

Os microrganismos encontrados neste estudo, antes e após a limpeza/desinfecção dos equipamentos, foram descritos no Quadro 1 com identificação do local e dos profissionais que os manipularam. 
Quadro 1. Microrganismos presentes nos equipamentos manipulados pela equipe multiprofissional da unidade de terapia intensiva, antes e após limpeza/desinfecção com álcool 70\%.

\begin{tabular}{|c|c|c|}
\hline Equipamentos & $\begin{array}{c}\text { Bactérias encontradas } \\
\text { antes da limpeza/desinfecção }\end{array}$ & $\begin{array}{c}\text { Bactérias encontradas } \\
\text { após limpeza/desinfecção }\end{array}$ \\
\hline Mesa de cabeceira & Sthafylococcus coagulase negativo & Não houve crescimento \\
\hline $\begin{array}{c}\text { Teclado de } \\
\text { computador }\end{array}$ & Sthafylococcus coagulase negativo & Não houve crescimento \\
\hline $\begin{array}{c}\text { Telefone } \\
\text { Bancada de preparo } \\
\text { de medicações }\end{array}$ & Sthafylococcus coagulase negativo & Sthafylococcus coagulase negativo \\
\hline $\begin{array}{c}\text { Glicosímetro } \\
\text { Escala de } \\
\text { enfermagem }\end{array}$ & Não houve crescimento & Não houve crescimento \\
\hline Monitor & Não houve crescimento & Não houve houve crescimento crescimento \\
\hline
\end{tabular}

Fonte: Dados coletados na Unidade de Terapia Intensiva de um hospital de médio porte, situado no interior de Minas Gerais, no período entre maio e agosto de 2017.

Das 7 superfícies analisadas, 4 não apresentaram bactérias, 3 apresentaram crescimento bacteriano de Sthafylococcus coagulase negativo apenas antes da limpeza/desinfecção; não houve crescimento após o procedimento. E uma das superfícies apresentou crescimento bacteriano de Sthapylococcus coagulase negativo antes e após o procedimento de limpeza/desinfecção ${ }^{(7-10)}$.

O Sthapylococcus coagulase negativo está presente na pele e mucosas do ser humano, é considerado um patógeno potencialmente causador de infecção relacionada à assistência a saúde, sendo comumente associado a infecções de corrente sanguínea, infecção de sítio cirúrgico, bacteremias, dentre outras. Esse patógeno vem aumentando sua resistência a antimicrobianos, e está relacionado na formação de biofilmes ${ }^{(10-15)}$.

Estudos mostram que a não higienização das mãos pode acarretar em contaminação ambiental e transmissão cruzada de microrganismos de um paciente para outro; portanto, este é um procedimento essencial em toda conduta e protocolo a ser realizado na assistência segura a um indivíduo, envolvendo 5 passos destinados aos cuidados antes e após o contato com o mesmo. Verifica-se que os procedimentos de higienização das mãos, antes do cuidado com o paciente, são os mais negligenciados, sendo o técnico de enfermagem, a categoria que tem menor adesão ao procedimento $^{(1,8)}$.

Além da prática de higienização das mãos, outra medida de segurança para o paciente é a descontaminação de superfícies, já que entram em contanto frequente com estes mesmos indivíduos e os profissionais envolvidos na assistência. A maioria das superfícies são consideradas como artigo não crítico, pois só entram em contato com a pele intacta do paciente; porém podem ser contaminadas por ele mesmo ou pelo profissional e, a partir disto, passam a ser objetos de transmissão cruzada. Sendo observada, em alguns estudos, a baixa adesão à higienização das mãos, podemos propor que a descontaminação de superfícies passe a ser um assunto que também deve ser analisado como prevenção de infecções e segurança do paciente.

Desta forma, a literatura nos apresenta que a desinfecção com álcool $70 \%$ se dá pela friç̧ão do mesmo por, no mínimo, 30 segundos. Precisamos levar em consideração que várias superfícies não são lisas e planas, merecendo cuidados em todos os lados a serem friccionados, além das reentrâncias que, muitas vezes, não podem entrar em contato com o álcool. Também precisamos levar em consideração a frequência de desinfecção dos equipamentos e estabelecer rotinas, de acordo com a sua utilização, ou seja, os mais manipulados devem ser descontaminados após o uso ou com uma frequência maior, e deve ser avaliada a utilização de luvas para o contato com eles, instituindo as precauções de contato e universal. $O$ aparelho telefônico, teclado de computador e bancada de preparo de medicamentos são superfícies, frequentemente, manuseadas pela equipe assistencial, portanto devem ser desinfetados com maior frequência e precisão na técnica, além da correta higienização das mãos para diminuir a contaminação ambiental ${ }^{(1,3)}$.

A estrutura física da UTI também deve obedecer aos critérios recomendados, como por 
exemplo: a existência de pias ou dispensers de álcool em gel próximos ao leito do paciente; a distância mínima entre os leitos; presença de lixos corretamente identificados, de acordo com a RDC 50/2002.

As limitações deste estudo foram: o pequeno número da amostra, o período restrito da coleta, a taxa de ocupação baixa do setor, sendo utilizado como critério, internação não inferior a 24 horas.

A aplicabilidade deste estudo objetivou propor um protocolo para descontaminação de equipamentos da unidade, alertando sobre a contaminação frequente deles ao serem manuseados sem higienização das mãos antes e após o contato com pacientes, materiais e outros equipamentos contaminados próximos ao leito do paciente.

Desta forma, segue sugestão de protocolo para descontaminação de equipamentos na unidade de terapia intensiva:

\section{Proposta de protocolo para descontaminação de equipamentos na Unidade de terapia Intensiva.}

A presença de sujidade e de matéria orgânica nas superfícies hospitalares serve como meio de proliferação de microrganismos na unidade de terapia intensiva. Desta forma, é de suma importância a higienização das mãos e a limpeza e desinfecção de superfícies para prevenção de infecção relacionada à saúde.

As superfícies hospitalares devem estar sempre limpas e secas. A unidade de terapia intensiva (UTI) é classificada como área crítica, considerando o seu potencial risco para transmissão de infecções ${ }^{(2)}$.

A estrutura física da UTI deve obedecer às normas vigentes como: no mínimo 2 metros de distância entre os leitos, com separação entre eles; entre leitos e paredes, 1 metro; pé da cama, 1,2 metros; o box deve ter, no mínimo, 3 metros de largura sendo 1 metro em cada lateral e mais 1 metro para a cama. Também deve haver 1 lavatório a cada 5 leitos de não isolamento com torneiras ou comandos que dispensem o contato com as mãos e a provisão de insumos necessários para lavagem das mãos como água, sabão e papel toalha. Quarto de isolamento com sanitário ou banheiro, para cada 10 leitos de UTI, e que deve ter antessala e lavatórios, exclusivos para uso da equipe, providos com bancada e pia de despejo. Também é importante reforçar sobre os materiais e equipamentos que devem ser individualizados para cada leito.
Os equipamentos utilizados na UTI que não podem entrar em contato com álcool $70 \%$ ou que não são lisos e planos, dificultando a limpeza e desinfecção, devem ser avaliados para aplicação de uma cobertura de plástico que se adapte ao equipamento para que seja possível realizar o procedimento.

A equipe multiprofissional atuante dentro da UTI como médicos, enfermeiros, técnicos de enfermagem, fisioterapeutas etc., deve obedecer às recomendações fornecidas pela comissão de controle de infecção hospitalar quanto às precauções utilizadas aos pacientes em isolamento.

Os profissionais atuantes na UTI devem ser capacitados e treinados para realizar higienização das mãos e as técnicas de limpeza e desinfecção de materiais e equipamentos.

As recomendações gerais para o profissional que irá realizar a limpeza e desinfecção de superfícies são: higienização das mãos, retirar adornos, utilizar os equipamentos de proteção individual (luvas, máscaras, avental, óculos) ${ }^{(2,16)}$.

Limpeza: é a remoção de sujidade mediante a utilização de água e sabão ${ }^{(4)}$.

Desinfecção: é um processo físico e químico que elimina a maioria dos microrganismos patogênicos das superfícies ${ }^{(4)}$.

Contaminação: presença transitória de microrganismos de material infeccioso em superfície, sem invasão tecidual ou relação de parasitismo. Pode ocorrer em objetos inanimados ou em hospedeiros, podendo ser direta ou indireta $^{(4)}$.

\section{CONCLUSÃO}

O presente estudo mostra que os microrganismos podem sobreviver em superfícies inanimadas, podendo ser, desta forma, fontes de colonização quando manipuladas pelos profissionais de saúde. Medidas para descontaminação ambiental devem ser adotadas pelo serviço de assistência à saúde, obedecendo aos critérios do protocolo indicado para descontaminação com álcool $70 \%$.

\section{REFERÊNCIAS}

1 - Cordeiro ALAO, Oliveira MMC, Fernandes JD, Barros CSMA, Castro LMC. Contaminação de equipamentos em unidade de terapia intensiva. Acta Paul Enferm. 2015;28(2):160-5. https://doi.org/10.1590/1982-0194201500027

2 - Santos NDV, Rotta ET, Silva CF, Deutschendorf C, Santos RP. Avaliação da limpeza terminal em 
uma unidade para pacientes portadores de microrganismos multirresistentes. Rev HCPA. 2013 [Acesso em 13 jan 2017];33(1):7-14. Disponível em: http://seer.ufrgs.br/index.php/hcpa/article/view/ 37024/25665

3 - Dutra LGB, Neto HBN, Nedel FB, Lobo EA. Prevalência de contaminação bacteriana em estetoscópios. Rev Inst Adolfo Lutz. 2013;72(2):155-60.

https://doi.org/10.18241/0073-98552013721557 4 - Valadares BDS, Barbosa RM, Teixeira RAV, Oliveira RADO, Tomich GM. Contaminação de uniformes privativos utilizados por profissionais que atuam nas unidades de terapia intensiva. Rev Epidemiol Control Infect. 2017;7(1):8-13. https://doi.org/10.17058/reci.v7i1.7380

5 - Oliveira AC, Viana REH. Adenosina trifosfato bioluminescência para avaliação da limpeza de superfícies: uma revisão integrativa. Rev Bras Enferm. 2014;67(6):987-93. https://doi.org/10.1590/0034-7167.2014670618 6 - Renner JDP, Carvalho ED. Microrganismos isolados de superfícies da UTI adulta em um hospital do Vale do Rio Pardo-RS. Rev Epidemiol Control Infect. 2013;3(2):40-4. https://doi.org/10.17058/reci.v3i2.3290

7 - Brixner B, Renner JDP, Krummenauer EC. Contaminação ambiental da UTI pediátrica: fator de risco para a ocorrência de infecções oportunistas?. Rev Epidemiol Control Infect. 2016; 6(1):24-8. https://doi.org/10.17058/reci.v6i1.6819

8 - Souza LM, Ramos MF, Becker ESS, Meirelles LCS, Monteiro SAO. Adesão dos profissionais de terapia intensiva aos cinco momentos da higienização das mãos. Rev Gaúcha Enferm. 2015;36(4):21-8. Disponível em: https://doi.org/10.1590/1983-

1447.2015.04.49090

9 - Nogueira LS, Ferretti-Rebustini REL, Poveda VB, Gengo e Silva RC, Barbosa RS, Oliveira EM, Adolhe R, Padilha KG. Carga de trabalho de enfermagem: preditor de infecção relacionado à assistência à saúde na terapia intensiva?. Rev Esc Enferm USP. 2015;49(Esp):36-42. https://doi.org/10.1590/S0080-

\section{$\underline{623420150000700006}$}

10 - Aycan IO, Celen MK, Yilmaz A, Almaz MS, Dal T, Celik Y, Bolat E. Colonização bacteriana por causa do aumento da carga de trabalho da equipe de enfermagem em unidade de terapia intensiva. Rev Bras Anestesiol. 2015;65(3):180-5. https://doi.org/10.1016/i.bjane.2014.05.005
11 - Sales VM, Oliveira E, Célia R, Gonçalves FR, Melo CC. Análise microbiológica de superfícies inanimadas de uma Unidade de Terapia Intensiva e a segurança do paciente. Rev Enferm Refe. 2014;4(3):45-53.

https://doi.org/10.12707/RIII1293

12 - Oliveira AC, Paula AO, Iquiapaza RA, Lacerda ACS. Infecções relacionadas à assistência em saúde e gravidade clínica em uma unidade de terapia intensiva. Rev Gaúcha Enferm.2012;33(3):89-96.

https://doi.org/10.1590/S1983-

14472012000300012

13 - Carvalho MR, Moreira ICCC, Amorin Neta FL, Guimarães MSO, Viana VGF, Oliveira FW. Incidência de bactérias multirresistentes em uma unidade de terapia intensiva. Rev Interdisciplin. 2015 [Acesso em 13 jan 2017];8(2):75-85. Disponível em: https://revistainterdisciplinar.uninovafapi.edu.br/ index.php/revinter/article/view/697/pdf 223

14 - Silva ARAS, Simões MLCL, Werneck LS, Teixeira $\mathrm{CH}$. Infecções relacionadas à assistência à saúde por Staphylococcus coagulase negativa em unidade de terapia intensiva neonatal. Rev Bras Ter Intensiva. 2013;25(3):239-44. https://doi.org/10.5935/0103-507X.20130041 15 - Candido TS, Bernardi ACA. Avaliação da Resistência a Antimicrobianos de Staphylococcus Coagulase Negativa Encontrados nas Grades dos Leitos em uma Unidade de Terapia Intensiva. J Health Sci.2016;18(1):33-6. https://doi.org/10.17921/2447-

8938.2016v18n1p37-40

16 - Biblioteca Virtual em Saúde. Descritores em Ciências da Saúde - DeCS. 2017 [Acesso em 13 jan 2017]. Disponível em: http://decs.bvsalud.org

Nota: O presente artigo faz parte do Trabalho de Conclusão de Curso da especialização em Enfermagem em Unidade de Terapia Intensiva do Centro de Estudos de Enfermagem e Nutrição- CEEN.

Recebido em: 01/08/2017

Aprovado em: 14/11/2017

Endereço de correspondência:

Juliana Ribeiro Mendes

Rua Isaias Andrade de Souza, no 1192

CEP: 38307-070 - Ituiutaba/MG - Brasil

E-mail: julianarmendes19@gmail.com 